\title{
CARLOTA PALMEROLA - KUÑa PARAGUAY
}

\author{
Margarita Durán Estragó* \\ Universidad Católica de Asunción, Paraguay
}

Resumen: La historia oficial del Paraguay está llena de héroes militares. Sus nombres están grabados en calles, avenidas, plazas, escuelas, clubes deportivos, comercios, hospitales, distritos, pueblos y ciudades del país. Las gestas guerreras llegaron a calar muy hondo en la identidad nacional, tanto que para el imaginario colectivo 'héroe' es sinónimo de soldado con fusil al hombro, gorra militar y bandera tricolor en mano. Si en esa historia queda poco lugar para héroes civiles, menos espacio tienen las heroínas, mujeres que supieron acrisolar virtudes en la cotidianidad del hogar, en orfanatos, escuelas, hospitales, chacras y actividades varias. Es el caso de Carlota Ayala (1853-1951) más conocida como Carlota Palmerola vecina del barrio Manorä (Recoleta), que a la edad de 14 años le tocó peregrinar como 'residenta' durante la Guerra Grande (1865 -1870). Su vida fue un ejemplo de trabajo, generosidad, austeridad y valor en la adversidad.

Palabras claves: Carlota Palmerola; Kuña Paraguay; Siglo XIX.

\section{Carlota Palmerota - Kuña Paraguay.}

Abstract: The Paraguay's official history is full of military heroes. Their names are engraved in the country streets, avenues, places, schools, sport clubs, commerce, hospitals, districts, villages and cities. The war exploits touched very deeply the national identity, that for the collective imaginary "hero" is the synonymous of a soldier with a self-loading rifle on his shoulder, a military cap and a tricolor flag in his hand. If this history doesn't left much place for civilian heroes, no less for heroines, women that knew how to purify virtues in their daily home, orphanages, schools, hospitals, ranches and other activities. It's Carlota Ayala's case (18531951), known as Carlota Palmerola, Manorã (Recoleta) quarter neighbor, that by 14 years old felt like going on pilgrimage as "resident" during the Guerra Grande (1865 -1870). Her life was an example of work, generosity, austerity and value during adversity times.

\footnotetext{
* Kuña Paraguay significa en lengua guaraní: Mujer paraguaya . La investigación para este artículo fue financiada por el Centro Cultural de España "Juan de Salazar" con miras a llevar al Teatro la vida de Carlota Palmerola (2008). El guión quedó a cargo del escritor paraguayo Guido Rodríguez Alcalá.
} 
Keywords: Carlota Palmerola; Kuña Paraguay; $19^{\text {th }}$ century.

La historia oficial del Paraguay está llena de héroes militares. Sus nombres están grabados en calles, avenidas, plazas, escuelas, clubes deportivos, comercios, hospitales, distritos, pueblos y ciudades del país. Las gestas guerreras llegaron a calar muy hondo en la identidad nacional, tanto que para el imaginario colectivo, héroe es sinónimo de soldado con fusil al hombre, gorra miliar y bandera tricolor en mano.

Si en esa historia queda poco lugar para héroes civiles, menos espacio tienen las heroínas, mujeres abnegadas que supieron acrisolar virtudes en la cotidianidad del hogar, en orfanatos, escuelas, hospitales, chacras y actividades varias. Es el caso de Carlota Ayala (1853-1951), más conocida como Carlota Palmerola vecina del barrio Manorä (Recoleta) que a la edad de 14 años le tocó peregrinar como 'residenta' durante la Guerra Grande (1865 -1870). Su vida fue un ejemplo de trabajo, generosidad, austeridad y valor en la adversidad. Uno de los escenarios más significativos de su larga existencia fue el castillo Palmerola, en Areguá, a orillas del lago Ypacarai.

\section{Villa veraniega de Areguá}

Las raíces de Areguá se remontan al siglo XVI. Junto al camino que conducía a los “indios de Tapaykua”, el gobernador Diego Ortiz de Zárate Mendieta otorgó en 1576 una merced real de tierras a Juan de la Torre, conquistador venido al Río de la Plata con don Pedro de Mendoza, en 1536. Esa concesión de tierras fechada el 5 de junio de 1576 y su asentamiento en ella, confirieron a Juan de la Torre el título de primer poblador español de Areguá.

Con el tiempo, parte de su heredad pasó a manos de los mercedarios por donación que les hiciera Ana de Estrada, viuda de Juan de la Torre, en 1624. Al año siguiente se establecieron en ella los frailes, junto al arroyo de las Tacuaras (Barrio las Mercedes). En 1641, recibieron nuevas donaciones de tierras de parte de Ana de Salazar, nieta y heredera legítima de aquel primer poblador. Con la suma de otros legados obtenidos posteriormente, los frailes de la Merced llegaron a poseer las tres cuartas partes de aquel feudo. Allí establecieron una estancia bajo el cuidado de una nutrida comunidad de negros, esclavos de dicha Orden religiosa.

En 1824, el doctor José Gaspar de Francia extinguió los conventos del Paraguay y sus bienes pasaron al Estado, entre ellos la estancia de Areguá. Los esclavos quedaron como propiedad del fisco, lo mismo el ganado que se incorporó a las estancias de la Patria. La llegada del ferrocarril despertó de su larga modorra al valle de Areguá. El propulsor de los "caminos de hierro", don Carlos Antonio López no alcanzó a inaugurar aquel tramo debido a su enfermedad y muerte acaecida en septiembre de 1862 . 
Uno de los primeros actos de gobierno de Francisco Solano López, quien sucedió a su padre en octubre del citado año, fue dotar al valle de Tapaykua de una jurisdicción propia, independiente de la de Itauguá. Para el efecto lo elevó a la categoría de distrito con la denominación de Areguá, el 13 de noviembre de 1862. La inauguración de la estación ferroviaria coincidió con la celebración de la Jura de la Independencia, el 25 de diciembre del mismo año. El viaje en tren y el Lago Ypacarai, la otrora laguna Tapaycua, se convirtieron en la máxima atracción de las familias capitalinas; hasta madame Lynch mandó construir junto al lago una lujosa residencia, frente a la estación Patiño kue (Itauguá). La bonanza duró muy poco: en mayo de 1865 las madres vieron partir a sus hijos para la guerra. Tras la toma de Asunción en enero de 1869, los brasileños resguardaron la vía férrea y construyeron una fortificación junto al muelle de Areguá. La guerra de exterminio siguió su curso; cuando ya no quedaron hombres hábiles para el manejo de las armas, "jóvenes de 12 años arriba" reclutados de todos los rincones del país (incluyendo Areguá) partieron para la guerra. En la batalla de Acosta Ñu, el 16 de agosto de 1869 ofrendaron sus vidas junto a las mujeres, ancianos y enfermos. El Paraguay fue reducido a escombros.

La población paraguaya estimada en 800.000 habitantes quedó disminuida a tan sólo un cuarto de ella. Ante tanta muerte, desolación y despojo, el Congreso Nacional trató de estimular y favorecer la concentración de familias y grupos humanos dispersos mediante la entrega gratuita de lotes, entre otras medidas. Para el efecto sancionó la ley del 28 de mayo de 1872 por la cual, las tierras pertenecientes al Estado, que hasta entonces eran inmensas, y las que se encontraban ubicadas en los pueblos de campaña dentro de un radio de unas siete cuadras, cuyo centro era la iglesia, debían ser divididas en manzanas y éstas en lotes para ser distribuidos gratuitamente. Esto a condición de que en el plazo de un año, el beneficiado tuviera edificada una vivienda "de ley", vale decir, una construcción sólida.

Entre tanto, Areguá como el resto de los pueblos fantasmas de la posguerra, seguía olvidado y pobre. Pasado el tiempo, las bondades que ofrecía Areguá con sus bellos paisajes y su clima apacible, sumadas a la facilidad de acceder a una fracción de tierra para vivienda, lo fueron convirtiendo, durante las dos primeras décadas del siglo XX, en la villa veraniega más importante del Paraguay.

Destacadas familias de Asunción iban adquiriendo sitios cercanos al lago, hecho que dio lugar a una carrera sin pausa de edificaciones de casas-quintas y chalets que competían en estilo, amplitud y belleza. Constructores de renombre como Miguel Cortina, Juan Bragulat y Vicente Gayete dirigían las principales obras arquitectónicas, mientras el comercio, la industria, la ganadería, agricultura y otras actividades comenzaron a prosperar de la mano de hombres y mujeres de negocios, tanto nacionales como extranjeros, que habían decidido radicarse en ella.

A juzgar por las crónicas periodísticas de aquella época, los veranos más 
publicitados y animados de Areguá se vivieron a partir de 1910. Esto se debió quizás al crecido número de familias veraneantes, casi todas provenientes del oficialismo liberal, lo cual facilitaba la convivencia y motivaba a sus integrantes a organizar todo clase de eventos culturales y sociales, que la prensa supo aprovechar en su momento. Suscitaban gran interés en los veraneantes las fiestas patronales y los carnavales celebrados en el mes de febrero, sin desmerecer los bailes de fin de año organizados en el Hotel Central, el Club Areguá o en alguna residencia particular. La rivalidad entre Areguá y San Bernardino comenzaba a sentirse fuertemente; la prensa se hacía eco de la misma y allá por los años veinte, cuando se publicaron las primeras fotografías en los periódicos, ambas villas veraniegas competían por los principales espacios y las mejores estampas de sus niñas en traje de baño, junto al lago.

El cierre del Hotel Central, el mejor y último de las tres primeras décadas, sumado a la falta de playas y al mal estado de sus calles, entre otros, fue marcando la diferencia con San Bernardino, en donde "el confort suplía el calor excesivo y la falta de aire que se siente entre las calcinadas piedras en que se asienta la colonia. De haber un hotel en Areguá como el que cuenta su rival en la orilla opuesta del lago", decía un cronista, "otro gallo cantaría". Aún así, Areguá siguió siendo el feudo preferido por las familias liberales adineradas, los intelectuales, artistas, hacendados, diplomáticos, comerciantes y políticos. A partir de la década del treinta, Areguá se retrajo y dejó de ser noticia en las páginas sociales; no obstante, las tradicionales familias asuncenas la seguían frecuentando, especialmente la gente mayor, amante de la placidez y del sosiego tan estimado en el ocaso de la vida. Desde entonces, Areguá quedó como congelada en el tiempo. Sus viejas casonas, muchas de ellas en lamentable estado de abandono, hablan por sí solas de su estancamiento. A pesar de sus incontables bondades naturales, su artesanía, su fruticultura y la calidad humana de su gente, Areguá no logra desarrollar su potencial turístico, capaz de mejorar la calidad de vida de su gente a partir de un sistemático aprovechamiento de sus recursos naturales.

\section{Carlota Palmerola}

En el límite noroeste de las tierras de Juan de la Torre (siglo XVI) se yergue hoy uno de los edificios más representativos de la ciudad de Areguá: el castillo Palmerola. Antes de adentrarnos en su interior, admirar sus dimensiones, deleitarnos con la majestuosidad de sus líneas y el delicado trabajo de sus rincones, empecemos por conocer a sus primeros moradores, principalmente a Carlota Ayala, viuda del hacendado correntino Toribio Palmerola.

Según la Heráldica, Palmerola proviene de "palma" o "palmera" y así figura en los escudos de tres familias Palmerola de Cataluña-España, de donde procede 
dicho apellido. Los Palmerola de Tárrega y Tarragona usaron oro, con una palmera de sable arrancada. Garma y Durán dice que los de la villa de Berga traían en campo de púrpura una corona de oro hueca, atravesada por dos ramas de palmeras, puestas perpendiculares y afrontadas. Pero en la sepultura que los Palmerola de Berga poseían en su iglesia de San Francisco, aparece este otro escudo como propio de ellos: de oro, con una rama de palmera de sinople. ${ }^{1}$ Los de Arxiu (Perpiñán), según un sello de Miguel de Palmerola, año 1789: en campo de oro, una palmera de sinople arrancada. ${ }^{2}$

Tal como lo señaláramos, Palmerola es un linaje de Cataluña muy antiguo y honorable, acaso originario del lugar de Palmerola, cuyo nombre tomara, perteneciente al partido judicial de Puigcerdá, en la provincia de Gerona. A principios del siglo XIV, una de sus principales ramas radicaba en la villa de Tárrega, del partido judicial de Cervera y provincia de Lérida, después se trasladó a Tarragona. En el año de 1369, cuando más encendida estaba la guerra entre los reyes de Aragón y Castilla, el infante don Juan, hijo primogénito del monarca aragonés don Pedro IV, pidió a los caballeros y nobles del campo y ciudad de Tarragona que acudiesen a ayudar a su padre, y uno de los primeros que respondió a este llamamiento, aportando sus armas, fue el caballero Ramón de Palmerola. Otra antigua rama de este linaje tuvo casa en la villa de Berga, de la provincia de Barcelona. En el siglo XVI tenía sepultura propia en la iglesia de San Francisco, de la citada villa. Otra residió en la localidad de Arxiu, departamento de Perpiñan (Catalunya Nord, actualmente Francia).

En la villa Palmerola de Gerona se conserva el castillo de los Palmerola, conocido popularmente como Castell de Pomerola. El mismo perteneció a Galcerón de Pinós y fue construido a comienzos del siglo XIII, luego pasó al conde de Vallfogona a partir de 1698; lo restauró y reformó hacia 1960 el marqués de Palmerola. La iglesia parroquial de San Vicente de Palmerola, situada junto al castillo, ya existía en el siglo XII y fue reconstruida en el XVII. Es una edificación de una nave, con capillas laterales y un pequeño y acogedor atrio abierto a sur. Fue restaurada parcialmente con la última rehabilitación del castillo. En lo alto de la entrada luce un renovado escudo de los Palmerola (corona con dos palmas). ${ }^{3}$

Los primeros Palmerola del Paraguay fueron los hermanos José y Toribio, que emigraron desde Corrientes (Argentina), al término de la guerra contra la Triple Alianza (1865-1870). Las revoluciones civiles que habían estallado en esa provincia empujaron a numerosos correntinos, entre ellos a muchos hacendados, a trasladar su ganado al Paraguay y afincarse en campos del centro y sur del país. ${ }^{4}$ Para el paso del ganado que venía de Corrientes fueron habilitados los puertos de Cerrito y Yabebyry sobre el río Paraná. ${ }^{5}$ Según versión de Juan Pucheu, los hermanos José y Toribio Palmerola formaron una sociedad antes de trasladarse al Paraguay, previa compra de un buen plantel de ganado vacuno y caballar y, al 
arribar a destino, rentaron un campo hasta asentarse en sus propias tierras. ${ }^{6}$ Después de unos años de trabajo y mucha suerte, decidieron poner en común sus bienes fundando la sociedad Toribio Palmerola Hnos. ${ }^{7}$ No se conserva la constitución de la sociedad; la misma aparece en los protocolos notariales del Paraguay a partir del 24 de agosto de 1877, fecha en que se inscribieron los campos de Caapucú denominados Rinconada de Sombrero y Cerro Campana.

Se tienen los nombres de sus padres: Juan Vicente Palmerola, vasco de nacimiento de acuerdo con Pucheu, aunque de origen catalán como queda expresado; al parecer fue el único de la familia que llegó a la Argentina, hacia 1830. Siguiendo al mismo autor — quien recogió la versión de Carlota Ayala, esposa de Toribio Palmerola - su madre fue Gregoria Almirón, “distinguida señorita paraguaya que vivía entonces en Corrientes". Además de los tres hermanos citados por este autor: Marcelino, José (1840) y Toribio (1842), documentos hallados en el Archivo Judicial de Corrientes dan cuenta de la existencia de Mercedes Palmerola, hija de Juan Vicente Palmerola, nacida en 1845, conocida como Mercedes Almirón "por haberse criado y educado en casa de una familia con este apellido". ${ }^{8}$ Damos como probable su arribo a la Argentina en la década del treinta ya que Mercedes, su cuarta hija, nació en 1845. Según acotación de Pucheu, Gregoria Almirón murió en el parto al nacer Toribio en 1842, lo cual abre un interrogante acerca de la identidad de la madre de esta última.

Siguiendo la versión del mismo autor, Juan Vicente Palmerola murió al cabo de unos años de viudez, quedando Marcelino Palmerola al cuidado de sus hermanos. Éste se casó durante la guerra de la Triple Alianza y en ese tiempo le tocó actuar como apoderado de los señores Lezica y Lanús, proveedores de los beligerantes. Al término de la guerra y por las causas ya señaladas, José y Toribio Palmerola emigraron al Paraguay, donde se establecieron y constituyeron sus respectivas familias. José Palmerola dejó descendencia, antes y durante su matrimonio con Gerónima Molas. Se conservan los nombres de Simeón, Felipa, Leovigilda, Froilán, Vicente, Dolores, María Ofelia, Zulmira Elisa del Carmen, Juan José Antonio, Félix, Josefa y María del Carmen Palmerola. ${ }^{9}$ José Palmerola sobrevivió a su hermano menor y murió en 1897. Sus hijos provenían de Caapucú y Pirayú donde poseía campos, también tuvo hijos con su esposa Jerónima Molas; hacia el año 1900 residían en Asunción, en la calle 5ta. Proyectada entre Yegros e Iturbe. No se conocen en el Paraguay hijos reconocidos de Toribio Palmerola que pudieran haber nacido durante los primeros años de su arribo al país, quizás los haya dejado en Corrientes de donde emigró con cerca de 30 años de edad. Pucheu habla de los "extravíos de su primera juventud"; recordemos que creció sin el amparo y afecto de su madre y que siendo niño, también perdió a su padre. Tras su llegada al Paraguay y su asentamiento en Campo Grande-Luque, Toribio Palmerola conoció a María Carlota Ayala, quien trabajaba para él de lavandera; ${ }^{10}$ ella era vecina del 
barrio Manorä (Recoleta) de donde procedía su familia. ${ }^{11}$ Carlota había nacido el 3 de noviembre de 1853 y era hija natural de Jerónima Ayala. ${ }^{12}$ Cuando la declaración de la Guerra contra la Triple Alianza (1865) Carlota era una niña de 12 años; vivió los horrores de la guerra al lado de su madre y sus abuelos maternos: Manuel Rosa Ayala y Lorenza Ayala. Durante el largo peregrinar de las residentas $;{ }^{13}$ estuvo a punto de caer en manos de la soldadesca en el pueblo de Pirayú; su abuela y otras mujeres ancianas que iban en la errante caravana la pudieron ocultar con disimulo; allí no terminó la tragedia, su madre no pudo soportó las penurias del éxodo y murió mientras la familia residía en Atyrá, ${ }^{14}$ en tanto que la joven quedó al cuidado de la abuela. ${ }^{15}$ Manuel Rosa Ayala fue condenado a muerte por el Tribunal Militar del mariscal Francisco Solano López; también sufrió torturas una sobrina de aquel, detenida por orden del militar Germán Serrano y el clérigo Fidel Maíz. Episodios como estos no se olvidan con el paso del tiempo, Carlota los siguió evocando hasta su muerte y Pucheu los recogió en su libro. ${ }^{16}$

Han quedado testimonios de vecinos del barrio de la Recoleta que en su momento declararon haber conocido a Toribio Palmerola hacia 1870; no sería desatinado pensar que el vínculo establecido entre esas personas y Palmerola haya surgido a partir de la amistad de Carlota Ayala con aquel inmigrante correntino ya adulto, cuando ella todavía era una adolescente tutelada por su anciana abuela. ${ }^{17}$ Tiempo después, Carlota pasó a vivir con Toribio Palmerola en la finca que éste había adquirido junto a la Isla Romero a orillas del Campo Grande; ${ }^{18}$ la compró en subasta pública en 1875, según Ley del 20 de agosto $1873 .{ }^{19}$ La misma le costó 5.025 pesos fuertes y consistió en cuatro cuerdas y media con frente al oeste y 14 cuerdas de fondo, lindando los cuatro costados con tierras fiscales. Dos años después compró en sociedad con su hermano José Palmerola las tierras de Caapucú, de las que ya se hizo mención. ${ }^{20}$

Toribio Palmerola construyó su vivienda en el sitio donde hoy se asienta el Hogar de Niños Carlota Palmerola y allí nacieron sus dos hijas: Ramona Josefa (1874) y Antolina Dolores (1875), a quienes reconoció como tales en su lecho de enfermo cuando in artículo mortis contrajo nupcias con su compañera Carlota Ayala, el 6 de diciembre de $1880 .{ }^{21}$ Declararon su soltería Sión Sosa y Gabriel Colmán, en tanto que el primero de los nombrados y la abuela Lorenza Ayala, actuaron como testigos de la boda. ${ }^{22}$ Toribio Palmerola se repuso de aquella enfermedad y la sociedad que llevaba su nombre siguió ampliando su patrimonio mediante la compra de buenos campos de pastoreo y nuevas partidas de ganado vacuno y caballar. En mayo de 1884, José y Toribio Palmerola adquirieron para dicho consorcio unas tierras en Cerro León-Pirayú; las mismas incluían la antigua residencia del mariscal Francisco Solano López, más conocida durante la Guerra contra la Triple Alianza, como Cuartel de Cerro León. ${ }^{23}$ Tres meses después de aquella inversión, Toribio Palmerola compró en Asunción un terreno con "casa 
de tejas" y allí mandó edificar su futura residencia; la misma corresponde hoy a la ferretería La Metalúrgica, ubicada en las calles 25 de Mayo y Paraguari, frente a la Plaza Uruguaya. ${ }^{24} \mathrm{Al}$ año siguiente pudo acrecentar sus tierras de Campo Grande ${ }^{25}$ y adquirir otra propiedad en Asunción. ${ }^{26}$ En 1886 logró ensanchar la primera finca adquirida en Luque once años atrás. ${ }^{27}$ Para entonces ya había dejado su humilde casa de Campo Grande instalándose con su familia en Asunción, en la nueva residencia de la calle Igualdad ( 25 de mayo) y Paraguarí. Toribio Palmerola se fue convirtiendo en un próspero hacendado, lo cual hizo que su familia viviera con holgura, aunque con sencillez y austeridad, como sencilla y austera era la vida de su esposa. La figura casi legendaria de Carlota Palmerola emergió vigorosa en medio de la quietud de su hogar a partir de la muerte de Toribio, en 1893. Pucheu la presenta como una mujer "chapada a la antigua: figura digna y austera, algo arcaica en su conducta y principios...persona de inteligencia viva y práctica, de voluntad férrea, de corazón delicado y atento hasta con sus propios adversarios, dotada por encima de todo de una elevación moral y de un espíritu de fe admirables". ${ }^{28} \mathrm{La}$ sociedad Toribio Palmerola Hnos. se disolvió tras la muerte de su titular, razón por la cual, los campos de Caapucú, Pirayú y Campo Grande fueron divididos entre José Palmerola y los herederos de Toribio. La administración de las haciendas heredadas de su esposo y la responsabilidad del hogar quedaron en manos de Carlota, quien, no solamente supo sostener aquellos campos y haciendas, sino que los acrecentó notoriamente, sin dejar de ser la mujer generosa y virtuosa de siempre. Con razón Pucheu la recuerda como la gran matrona paraguaya.

Carlota distribuía su tiempo y responsabilidad entre la residencia de Asunción y las estancias de Caapucú y Pirayú (Cerro León). En este lugar vivía Cornelio Bruyn, joven holandés al servicio del ferrocarril, quien conoció a Ramona Josefa Palmerola, hija mayor de Carlota. Entre tanto, Antolina Dolores formalizaba su compromiso matrimonial con Héctor Aceval, hijo de Benjamín Aceval y Juana Bautista Mongelós Egusquiza. Meses antes de cumplirse el tercer aniversario de la muerte de Toribio Palmerola, la residencia de la calle Igualdad se vistió de gala para la celebración de las bodas de las hermanas Palmerola. El 15 de febrero de 1896, en una misma ceremonia religiosa contrajeron nupcias las veinteañeras Ramona Josefa Palmerola y Cornelio Bruyn ${ }^{29}$ y Antolina Dolores Palmerola con Héctor Aceval, ${ }^{30}$ siendo Carlota Ayala madrina de ambas parejas; apadrinó a la primera Luis Patri, acaudalado hombre de negocios, en tanto que el padrino de Héctor y Antolina Dolores fue Benjamín Aceval, diplomático, magistrado y catedrático de gran renombre. La nueva familia Bruyn Palmerola fue a vivir a Cerro León y allí nacieron los primeros de sus seis hijos: Toribio Cornelio Jerónimo Eulalio (1896), Benjamín Héctor (1898), Damián Jacobo (1899), Florencio Sergio (1902), Edulia Cora (1906) y Juana Carlota Margarita Gertrudis (1911). En tanto que los esposos Aceval Palmerola se instalaron en Asunción, donde, a sólo dos días de diferencia 
de la hermana, Antolina dio a luz a su primer hijo Juan Carlos Martín, el 12 de diciembre de 1896; a éste siguió María Dianora Teresa de Jesús Tomasa (1897) y Toribio Emilio Isidro, dos años más tarde. ${ }^{31}$

Antolina quedó con tres niños pequeños al tiempo de separarse de Héctor Aceval, quien, a juzgar por la tradición familiar, causó muchos sufrimientos a su esposa. A partir de entonces, hacia comienzos del siglo XX, Carlota amparó a su hija menor y a sus nietos Juan Carlos, Dianora y Emilio formando con ellos una sola familia.

\section{Castillo Palmerola}

Cuando comenzaron a llegar los primeros nietos, Carlota pensó disponer para ellos de una casa de campo cercana a la capital. El pueblo de Areguá, con su lago, cerros, valles y lomas le pareció el sitio apropiado. La oportunidad se dio en 1897 cuando Eleuterio Correa vendió a Carlota Ayala de Palmerola una quinta compuesta de nueve fracciones de terreno. La superficie total del campo deslindado fue de 19 cuadras cuadradas, de las cuales se reservaron dos cuadras y 5.200 varas para utilidad pública y puerto de embarque sobre el lago Ypacarai. ${ }^{32}$ Según los antecedentes del título, el predio donde se levantó años más tarde el castillo Palmerola había sido adjudicado en forma gratuita a Juan de Freitas Travassos conforme a la mencionada ley de 1872; el mismo fue escriturado el 3 de agosto de 1887 por el presidente de la corporación, Calixto Fretes. Cuatro años después, Freitas Travassos formó sociedad con Victorino Gómez y Eleuterio Correa con el fin de explotar una fábrica de ladrillos en Areguá, un campo en Pirayú y las posibles canteras que podría haber en ellos. Los terrenos de Areguá se hallaban ubicados frente a la estación del ferrocarril, lindando al norte con el Lago Ypacaraí. Una de las fracciones limitaba justamente con el histórico arroyo de las Tacuaras, conocido entonces como arroyo Areguá por haber perdido su antigua denominación. Cinco de las nueve fracciones pertenecieron a Eleuterio Correa por compra hecha en condominio con José Victorino Gómez a Juan de Freitas Travassos en fecha 27 de febrero de 1892; otras tres le correspondieron por disolución de la sociedad José Victorino Gómez y Juan de Freitas Travassos y una última, por compra a Matías Barrios, en 1892. Las propiedades solicitadas por doña Carlota contaban con dos hipotecas, una a favor del Banco Agrícola del Paraguay y la otra a favor de Cristian Heisecke, Adolfo Saguier y Pacífico de Vargas. La compradora pagó por aquellos terrenos 31.000 pesos fuertes de curso legal, al contado. Estuvieron presentes en el acto de otorgamiento: Germán Pereira Cazal, Cristian G. Heisecke, Pacífico de Vargas y Adolfo Saguier, todos vecinos de Asunción; los tres últimos asistieron en propia representación; el primero en carácter de administrador del citado Banco Agrícola del Paraguay y en representación del mismo declaró canceladas las 
respectivas hipotecas en virtud de haber recibido, de manos de Eleuterio Correa, el importe del capital adeudado, más los intereses. ${ }^{33}$ Carlota pasaba la mayor parte del tiempo en Cerro León desde donde administraba sus estancias y compartía su vida con sus demás nietos. Al parecer, sus tierras de Areguá también las dedicó a la ganadería, es por eso que en la Guía General del Paraguay de 1908 aparece Carlota Ayala de Palmerola como una de las hacendadas del lugar, lo mismo su yerno Cornelio Bruyn, quien en 1906 y 1908 había comprado tierras y edificado una casa quinta cercana a la mansión que su suegra. Conviene señalar que hacia $1910 \mathrm{el}$ castillo Palmerola todavía estaba en obra y con andamios, según viejas fotografías que aún cuelgan en las paredes de aquella casona ubicada frente a la estación del tren. Poco o nada se sabe acerca de la edificación de la residencia de los Palmerola en Areguá. Según una nota periodística de La Tribuna, la construcción se inició en 1904, el mismo año en que Hipólito González dejó concluida la fachada de su residencia, la actual Villa Gisela, grabando en sus dos puertas principales, el año de 1904 y en la otra, sus iniciales HG. Ante tanta carencia documental, nos atrevemos a lanzar alguna hipótesis sobre los motivos que pudieron haber inducido a doña Carlota a imprimir en su nueva residencia, cierta reminiscencia medieval. Recordemos que en Cataluña se conserva el Castillo Palmerola y que uno de los principales constructores de las villas veraniegas de Areguá de comienzos del siglo XX fue precisamente el catalán Juan Bragulat. Es probable que éste hubiera sugerido a la viuda de Palmerola la idea de emular al castillo de sus antepasados, de donde procede dicho apellido, incorporando a la edificación, almenas y torreones a semejanza de aquel baluarte antiguo. El autor de la citada guía de 1908 describe a la villa veraniega de Areguá como uno de los pueblos predilectos de las familias asuncenas y lo sitúa entre los más pujantes de la época por sus cómodos hoteles, numerosas fábricas, establecimientos industriales, su club social "recientemente terminado" y los hermosos palacetes y chalets levantados en las cercanías del lago. Llama poderosamente la atención que dicha guía no haga ninguna mención del castillo Palmerola ya que de haber existido, no pudo haber dejado de nombrarlo entre la treintena de residencias construidas al tiempo de aquella edición, salvo que la haya escrito mucho antes de su edición. Si realmente la obra comenzó en 1904, la misma tuvo que haber quedado suspendida a poco de iniciarse los trabajos, en tanto que su construcción y finalización la podríamos calcular hacia 1911. A partir de entonces la familia Palmerola pudo haber trasladado su residencia a Areguá.

Siguiendo con lo apuntado en La Tribuna acerca del estilo arquitectónico del castillo, éste fue "diseñado por el arquitecto $\operatorname{Hoffer}^{34}$ y construido bajo la supervisión del ingeniero Pascuasi" (sic). Al no contar con ninguna otra referencia ni conocer el nombre del autor de dicho artículo, aunque nos parece serio, nos limitamos a mencionar lo allí expresado. Como toda construcción de comienzos del siglo XX, ella toma algo de cada estilo. Mirando al castillo de frente, dice la citada 
información, "parece que las columnas finas y alargadas sostienen la gran masa del techo dando un aire etéreo al edificio. En realidad, estas columnas solamente sostienen un techo alero encima de la galería. Debajo de las almenas románticas hay una franja con grabados muy elaborados parecidos a una obra rococó a la inglesa. Dos torres se proyectan de las almenas. La torre a la derecha es masiva y curvilineal con unas almenas románticas que siguen la línea del edificio. La de la izquierda es muy pequeña, de un estilo gótico a lo medio oriental que desequilibra al edificio por su tamaño y estilo. Siguiendo el tono arábico están las aberturas ovaladas del frente que son una adaptación entre lo inglés y lo medio oriental. Al costado, las aberturas de las ventanas son rectangulares, cortadas dentro de la pared, creando una imagen oscura y hundida. La barandilla que acompaña la escalera y rodea la galería es reminiscencia de los edificios renacentistas italianos.

Pese a toda esta variedad de estilos, la impresión que produce la estructura es neoclásica italiana. La vegetación tropical como los cocoteros gigantes y los cipreses cortados que se extienden a lo largo del camino de entrada ayudan a situar el castillo como una de las tantas ruinas en la campiña italiana". ${ }^{35}$ Una vez instalados los Palmerola en Areguá, la vida cotidiana debió transcurrir tranquila y apacible en aquella mansión recién estrenada, rodeada de una exuberante vegetación y con la legendaria laguna Tapaykua a sus espaldas. Sólo el paso del tren podía perturbar tanta paz y armonía. Una numerosa servidumbre se encargaba de los quehaceres domésticos y el cuidado permanente de los nietos, siempre bajo la atenta mirada de la abuela Carlota y la madre Antolina. Para entonces, Juan Carlos debió haber tenido unos 14 años, María Dianora 13 y Emilio 11. Hasta el momento no habían asistido a ninguna escuela, siendo su madre la encargada de darles las clases en su propio domicilio, primero en Cerro León y luego en Areguá. Recordemos que Antolina poseía una buena formación intelectual; dominaba el francés tal como lo demuestran ciertos apuntes y cartas de su puño y letra que todavía se conservan en los escritorios del castillo como testimonio de una época perdida en el tiempo. Aun así, los pequeños contaron con una maestra particular, la señorita Balbina Olaizola, hermana quizás del cura párroco de Areguá, Constantino Olaizola.

Poco tiempo duró aquella docencia ya que en 1909, a pocos años de abrirse en Asunción las puertas del Colegio San José, del que doña Carlota era benefactora, sus nietos Juan Carlos y Emilio ingresaron en dicha institución como alumnos internos durante los dos primeros años, lapso en que el mayor completó el ciclo primario; también ingresó su nieto Toribio Bruyn Palmerola como alumno del primer curso del bachillerato. ${ }^{36}$ Por voluntad expresa de doña Carlota no hubo privilegios para estos escolares, que cumplieron las exigencias del reglamento como los demás estudiantes. Siendo alumnos del citado colegio, ambos hermanos recibieron la Primera Comunión, recuerdo estampado en viejas fotografías. Su hermana María Dianora ingresó en el Colegio María Auxiliadora en 1911, a la edad de 13 años, ${ }^{37}$ 
época en que también recibió la Primera Comunión como correspondía a una niña proveniente de una familia cristiana. La hija mayor de doña Carlota dejó Cerro León para residir con su familia en el nuevo chalet de Areguá, el cual fue edificado detrás de la Estación del Ferrocarril, y era el mismo que en 1908 ya figuraba entre las villas veraniegas del lugar. ${ }^{38}$ La cercanía de ambas familias hizo que los primos hermanos pudieran disfrutar juntos de sus juegos al aire libre, en especial de la pelota vasca para lo cual la abuela Carlota mandó construir un frontón de grandes proporciones, a la derecha del castillo, tal como se puede apreciar en una de las fotografías del libro de Pucheu..$^{39}$ Dicho deporte era poco conocido en el Paraguay, lo que lo hacía más atrayente a los pasajeros del tren en su travesía por Areguá, lo mismo a los lugareños que se asomaban al cerco de la propiedad para ver jugar a aquellos jóvenes mimados por la fortuna. A pesar de tanta holgura económica, la familia Aceval Palmerola conoció de infortunios a causa de la falta del padre en el hogar y de la delicada salud de María Dianora, que le impedía tomar cursos regulares en el Colegio María Auxiliadora donde ingresó en 1911. No obstante, estuvo como pupila en dicha institución religiosa durante varios meses, al cabo de los cuales le sobrevino una ligera pero persistente fiebre que se fue complicando, motivo por el cual no pudo volver al colegio. Meses después de haberse restablecido de aquella dolencia le vino una recaída que la llevó a la muerte con tan solo 15 años de edad cumplidos en el mes de diciembre anterior, el 29 de enero de $1913 .{ }^{40}$ La profunda fe cristiana profesada por la abuela Carlota y transmitida por ésta a su familia fue lo único que pudo sostenerlas en tan penoso trance. La vida apacible y feliz en el castillo Palmerola nunca más volvió a ser la misma; todo cambió para sus moradores. La triste noticia de la partida de María Dianora Aceval Palmerola también tuvo su impacto en el reducido vecindario y principalmente entre los veraneantes asuncenos, que para entonces pasaban sus vacaciones en Areguá. La vida continuó su curso, y también la generosidad de doña Carlota, que a pesar de aquella desgracia sacó fuerzas para seguir ayudando a todos, en especial a la Iglesia y a las comunidades religiosas del Colegio San José y María Auxiliadora. Ella fue una de las principales benefactoras de las obras del templo de Areguá propiciadas por el padre Constantino Olaizola y habilitadas durante los festejos patronales de la Candelaria de 1915. Se trataba de la inauguración de la torre de la iglesia bendecida por el obispo del Paraguay, monseñor Juan Sinforiano Bogarín. ${ }^{41}$ También aportó para la construcción del matadero y del mercado municipal de Areguá; la remodelación de la casa parroquial; el muelle sobre el lago Ypacarai; la conformación de una banda municipal, entre otras cosas. Las idas y venidas en tren se volvieron rutinarias para Carlos y Emilio, como para sus primos, que también iban al Colegio San José desde Areguá. El encuentro con sus compañeros y amigos en el castillo Palmerola era frecuente, principalmente durante las vacaciones de verano; añejas fotografías perpetúan esos momentos. Al fin llegó para Carlos la 
conclusión de sus estudios secundarios en 1916, aunque no por eso dejó de ocuparse de su colegio. Con la colaboración de otros compañeros, trabajó en la elaboración de unos estatutos con miras a fundar la Asociación de ex alumnos del Colegio San José, llegando a integrar su primera comisión directiva en calidad de tesorero de la misma. Le interesaban el Derecho, la Filosofía y las Ciencias Sociales y dedicaba sus ratos libres a esculpir guampas. También se sintió atraído por las actividades ganaderas, ayudando a su abuelita en la administración de las estancias. Adiestraba caballos para tirar coches en los que se pudieran movilizar sus "dos madres" cuando debían viajar a Caapucú o subir la cuesta hasta el templo de Areguá. La cacería fue otra de sus aficiones, lo mismo la esgrima, la pelota vasca y el boxeo. Cursaba el segundo año de Universidad en la Facultad de Derecho y Ciencias Sociales cuando, en 1918, sobrevino una virulenta epidemia que obligó incluso la suspensión de las festividades de Caacupé de aquel año. Doña Carlota pretendió refugiarse con su familia en Cerro León, pero al enterarse de la propagación del mal en aquella región, decidió permanecer en Areguá. Cuenta Pucheu que a fines de diciembre de aquel año llegaron a la residencia de los Palmerola dos sacerdotes del Colegio San José que ocasionalmente habían pasado unos días en San Bernardino. El encuentro en Areguá con los ex alumnos fue celebrado por todos y al día siguiente, a pedido de doña Carlota pudieron participar juntos de una misa en la capilla familiar. ${ }^{42} \mathrm{Carlos}$ Aceval Palmerola se desempeñaba entonces como presidente de la Asociación de Ex - alumnos del Colegio San José. Fue la última Comunión que recibiera Juan Carlos Aceval Palmerola, pues dos días después tuvo que guardar cama a causa de una fiebre, benigna en un principio, pero la enfermedad siguió avanzando y con ella la fiebre. No había médicos en Areguá y cuando tardíamente pudieron llegar dos galenos desde Asunción, lo primero que pidieron fue un trozo de hielo para tratar de bajar la fiebre, que no se pudo encontrar en el pueblo. A seis años de la partida de su hermana Dianora y con sólo 22 años de edad cumplidos en diciembre pasado moría en Areguá Juan Carlos Aceval Palmerota, el nieto predilecto de doña Carlota; era el 10 de enero de 1919.

Quedaba el último de los hermanos, Emilio, de carácter alegre e inteligencia clara, según su biógrafo. De los tres, fue el único que pudo culminar sus estudios universitarios y lo hizo en tan sólo cuatro años, consiguiendo el título de abogado después de defender la tesis. Aun estando en la Universidad llegó a ser presidente de la Federación de la Juventud Católica, en tiempos en que el anticlericalismo se imponía entre los intelectuales, resultando vergonzante la asistencia de los mismos en celebraciones litúrgicas y actos religiosos.

También en la villa veraniega Emilio llegó a participar de las actividades culturales y recreativas organizadas por las familias asuncenas; lo vemos por ejemplo, a comienzos de 1923 en el Club Areguá dando la bienvenida a los integrantes de la Asociación de Exploradores Paraguayos en su paso por ella. ${ }^{43}$ 
La festividad de la Virgen del Carmen de 1925, fue celebrada por doña Carlota y los suyos en su residencia de Areguá - ella había sido muy devota de la Virgen, desde los años de la guerra-. En el piso alto de la mansión tenían un oratorio doméstico y en su entorno se reunió la familia y sus allegados - entre ellos la infaltable Estanislaa, anciana señorita amiga de la casa y el padre Constantino Olaizola, quien celebró una misa ante aquella imagen, en sufragio del alma de Juan Carlos. Horas después, previo desayuno y amena charla con el cura párroco, Emilio y doña Carlota se dispusieron a viajar a la capital por asuntos de negocios. Al regresar por la noche, el joven manifestó un ligero dolor intestinal que le impidió cenar. A medianoche despertó con fuertes dolores estomacales seguidos de vómitos; la madre le preparó cuantos remedios caseros conocía hasta que el dolor cesó, pero entonces apareció la fiebre y, con ella, las violentas convulsiones. Emilio se sentía muy débil para viajar hasta Asunción en busca de una mejor atención médica. E1 mal persistió y un tren expreso venido de Asunción esperó la orden del médico para trasladarlo hasta un sanatorio. En su lecho de enfermo confesó a su madre que había jurado sobre la tumba de su hermano hacerse sacerdote y que lo cumpliría una vez recuperada su salud.

Llegó la hora de la partida. Cuenta su desconsolada madre que en vez de un furgón trajeron un coche de primera clase, por lo que hubo que colocar la camilla sobre los asientos, después de haberlo introducido con mil penurias y sufrimientos del enfermo. Al operar el joven, los cirujanos encontraron varios focos infecciosos, lo cual les hizo desesperar de una curación. Emilio Aceval Palmerota murió tras siete días de agonía, el 23 de julio de 1925; contaba con 26 años de edad cumplidos en mayo pasado y dos de abogado.

Sus exequias reunieron a lo más granado de la intelectualidad paraguaya, lo mismo a la jerarquía eclesiástica, la clase política, ex alumnos del Colegio San José, parientes y amigos de la familia. ${ }^{44}$ En el castillo Palmerola quedaron las dos mujeres solas. Una sobrevivía por sostener a la otra, mientras que ambas desfallecían de dolor e impotencia ante tanta adversidad. La hija mayor de doña Carlota pasó a residir con su familia en el chalet ubicado junto al castillo para acompañar de cerca a su madre y hermana. Doña Carlota fue una mujer de dolores, aunque de una fe inquebrantable. Seis meses después de aquel tres veces duro golpe, apadrinó junto al pa'i Olaizola, Juan José Manzoni y otros benefactores de la parroquia de Areguá, la bendición de una imagen de Santo Domingo de Guzmán adquirida en España, a iniciativa de José Goyburú. ${ }^{45} \mathrm{Su}$ generosidad no tenía límites: las corridas de toros de la festividad de la Candelaria de 1927 también se hicieron con animales de su establecimiento, como era costumbre; tampoco dejó de ayudar al Seminario y demás instituciones religiosas. Su gran devoción a la Virgen del Carmen la llevó a levantar una capilla de grandes proporciones en el patio de su residencia. La obra estuvo a cargo de su nieto Cornelio Bruyn 
Palmerota y la construcción data de $1937 .{ }^{46}$ Una década más tarde, doña Carlota donó su casa de Campo Grande al Arzobispado; era su deseo convertirla en hogar infantil. Monseñor Bogarín entregó dicha propiedad a las hermanas dominicas, el 17 de mayo de 1948 y desde entonces, aquellas tierras con sus instalaciones conforman el Hogar de Niños Carlota Palmerota, bajo la dirección de las citadas religiosas ${ }^{47}$ Larga vida le tocó vivir a doña Carlota, siempre en compañía de su desdichada hija Antolina Dolores, madre de aquellos tres jóvenes que murieron a los 15, 19 y 27 años respectivamente. Contaba doña Carlota con 92 años de edad cuando el Papa Pío XII le otorgó una distinción especial por tantos favores prodigados a la Iglesia del Paraguay. Todavía le quedaban unos años de vida cuando la trasladaron definitivamente a su residencia de la calle 25 de Mayo, en Asunción. Allí falleció el 27 de mayo de 1951, a los 97 años de edad cumplidos en noviembre del año anterior. ${ }^{48}$ Doña Antolina regresó al castillo de Areguá en compañía de su criada China y en 1959, siguiendo la tradicional generosidad de su madre, donó a las Hermanas Dominicas dos hectáreas de terreno, incluyendo en ellas el castillo Palmarola de Areguá. ${ }^{49}$ Un informe presentado ante a las autoridades eclesiásticas por dicha congregación religiosa, ese mismo año de 1959, da cuenta de la "Casa de Areguá" como "recientemente donada a la Congregación" y la señala como "deshabitada". ${ }^{50}$

Aunque doña Antolina se había mudado a la casa contigua al castillo (que según descendientes de doña Carlota se construyó para obsequiarle a su nieta Dianota), ella había dispuesto que el traspaso del mismo a las hermanas se hiciera después su fallecimiento. No obstante, a finales de 1963, en vida de la misma, aquellas obtuvieron permiso para trasladar allí el noviciado de la Congregación. Desde entonces, aunque con otros fines, las dominicas lo siguen ocupando. Las hijas de Carlota también murieron longevas: Josefa Ramona en 1963 a los 89 años, y Antolina Dolores en 1967 con 92 años de edad. Josefa Ramona dejó descendientes: los Bruyn Palmerola, que se unieron en matrimonio con integrantes de reconocidas familias de la sociedad como son los Facetti, Carrizosa, Bibolini, Porta, entre otros.

En cuanto al castillo Palmerola, su conservación preocupa a propios y extraños. Su mantenimiento resulta costoso y la Congregación de Hermanas Dominicas no cuenta con fondos para ello. Un artículo periodístico de 1974 ya señalaba su constante deterioro y la necesidad de urgentes reparaciones, señalando: "Las almenas superiores se encuentran deterioradas, así como los techos".

Ya entonces se hablaba de una "imperiosa necesidad de revisión total cuando menos, de lo contrario, añadía el articulista, se corre el riesgo de perder una valiosa pieza arquitectónica" y agregamos, un testimonio vivo de la memoria histórica de los Palmerola en el Paraguay, principalmente de Carlota, heroína del Paraguay profundo. 


\section{NOTAS}

I Color que en pintura se representa con el verde.

2 Doménech y Roura, F. Nobiliari general Català, volumen II, cuadernillo XVI, lámina CXXXVII, Barcelona, 1927 (Gentileza de Eduardo García, desde Barcelona-Cataluña).

3 Pla, Josep S.A. Editora. Enciclopedia Catalana. XV Volúmenes. Barcelona - España. $1970-2005$.

4 CASTELLO, A. E. Historia llustrada de la Provincia de Corrientes, Resistencia-Chaco: Editorial Cosmos, 1996. GOMEZ, Hernán Félix. "Naembe" (Crónicas de la guerra de López Jordán y de la epidemia de 1871), Corrientes, 1997. Estos y otros autores hablan de los levantamientos armados y las revoluciones que se produjeron en Corrientes desde 1868 en adelante; la de I87I, época en la que posiblemente emigraron los Palmerola, se dio durante el gobierno de Agustín P. Justo, electo en forma fraudulenta el 25 de diciembre de 187|, con apoyo de algunas facciones de liberales. Poco después, el gobierno empezó a detener a los opositores, levantándose en armas la facción de los liberales que respondían al héroe de la Guerra contra el Paraguay, el coronel Desiderio Sosa. Los enfrentamientos armados se sucedieron hasta culminar con la batalla decisiva librada el 4 de marzo de 1872, donde en las Lomas del Tabaco, las fuerzas de Sosa, derrotaron al ex Gobernador Baibiene, sostenedor de Justo. Los vencedores respondían a Sarmiento, mientras que los vencidos eran mitristas y se vieron obligados a emigrar. (Gentileza de Carlos Romero Jensen - Corrientes - Argentina).

5 PASTORE, C. La lucha por la tierra en el Paraguay. Montevideo: Editorial Antequera, 1972, p. 210.

6 PUCHEU, J. S. C.J. Una Familia Paraguaya (Asunción, 1930), p. 20. No se pudieron corroborar los datos recogidos por este autor. En el panteón de la familia Palmerola del Cementerio de la Recoleta reposan, entre otros, los restos de Toribio Palmerola ( | 8-X||- | 842 / 27-VI|- | 893) y de su hermano José Palmerola ( 19-I||- 840 / | 7-IV- | 897).

7 Archivo del Registro General de la Propiedad, Año 1877, Tomo 1.500, f. 610.

8 Archivo Judicial de Corrientes. Juicio sucesorio de Juan Vicente Palmerola y su hija Mercedes Palmerola tramitado por Enrique Palliso, bisnieto del primero y nieto materno de la segunda, fechado en 1904. En dicho documento se deja constancia que no se ha encontrado la partida de nacimiento ni la defunción de Juan Vicente Palmerola.

9 Archivo del Registro General de la Propiedad. Año 1900, Tomo 390, f. 665 V.

10 Archivo Arzobispal de Asunción. Libro II. Recoleta. Bautismos 1853-1878. Partida de bautismo de Carlota Ayala celebrado por el cura Cornelio Contreras, el 4 de noviembre de 1853, p. 34. La tradición familiar de los Bruyn Palmerola recuerda a Carlota Ayala como la joven lavandera de don Toribio Palmerola

II ANA CRB Vol. 37I. Año. 17. Hemos hallado en el Archivo Nacional de Asunción el dibujo de un plano donde aparece el camino de Manorá (Recoleta) y en sus orillas, mojones y casas de vecinos, entre ellos, los de los Ayala y muy próximos a éstos los de Cirilo López y Melchora Insfrán, padres de Carlos Antonio López, primer presidente constitucional del Paraguay ( 844 1862).

12 Archivo Arzobispal de Asunción. Bautismos I. Recoleta Primer libro de bautismos abierto en 1829, año de la creación de dicha parroquia. No. 568, f. 79 v. Partida de bautismo de Jerónima Ayala celebrado el I de octubre de 1835, hija de Lorenza Clara Ayala y Manuel Rosa Ayala. La ceremonia estuvo a cargo del cura Manuel Orué. Fueron sus abuelos maternos Juan Mauricio Ayala y María Isabel Fretes y su abuela paterna Marcelina Ayala (difunta).

13 Se les llamaba residentas a las mujeres (cabezas de familia en ausencia del varón) que iban 
cambiando de "residencia" por orden de López, conforme iban avanzando las fuerzas aliadas. Con ese apelativo se las quería diferenciar de las "vecinas" del lugar donde aquellas moraban ocasionalmente. Es errónea la noción de "residentas" como sinónimo de "mujeres que seguían a López".

14 PUCHEU, op. cit., p.

I5 ANA Libro de Registro de las manifestaciones de joyas y alhajas de las ciudadanas paraguayas para aumentar los elementos de la defensa de la Patria. Vol. I, Asunción, 24 de julio de 1867. Allí están consignadas las joyas que entregó Lorenza Ayala: Una cadena de oro con peso de 15 adarmes. Un par de zarcillos de oro de tres pendientes, con seis topacios finos. También figuran otras Ayala de Recoleta que con seguridad fueron familiares de Carlota. Archivo Arzobispal de Asunción. Matrimonios I. Recoleta. Libro de Casamientos correspondientes a la Iglesia parroquial de la Recoleta fundada en el año 1829. No. 74, f. 23. Certificado de matrimonio de Manuel Rosa Ayala y Lorenza Clara Ayala celebrado el 27 de noviembre de I 834. "Se casaron con misa nupcial, en la que comulgaron". Fueron testigos de la boda José Guillermo Pérez y María Pascuala Gavón, ofició el sacerdote Julián Manuel Orué.

16 PUCHEU. Op. cit., pp. 18 y ss. Documentos de archivo dan cuenta que el abuelo de Carlota Ayala fue Manuel Rosa Ayala y no Francisco Ayala como lo identifica este autor.

17 Archivo del Arzobispado de Asunción. Parroquia de Luque. Partidas de Matrimonios ( $843-$ |89|). Los testigos que declararon conocer a Toribio Palmerola desde hacía 10 años fueron Gabriel Colmán y Sión Sosa, en fecha 6 de diciembre de 1880.

I8 ANA Propiedades Vol. 4 I 4 No.2. En el Plano General de la Ciudad de Asunción de Federico E. De Gásperí aparece la Isla Romero ubicada al norte de las tierras de Palmerola. Cabe destacar que doña Antolina Palmerota de Aceval donó esas tierras y todo lo en ellas plantado y clavado a las Hermanas Dominicas, en 1948, se trata del actual Hogar de Niños Carlota Palmerola. La zona sigue conociéndose como Curva Romero, nombre proveniente del apellido de la familia que la ocupó desde mediados del siglo XIX. En efecto, Manuel Romero y Juana Gamarra compraron aquella "isla" de María Ana Peñaroja en 1849 heredera de Josefa Rosa Peñaroja, madre de Juan Vicente Medina quien a su vez había recibido aquellas fincas por herencia que le dejara su padre Tomás Martín Medina ( 18 |3) nacido en Bessin, Guipúzcoa -España. Los antecedentes de título de los Romero se pudieron conocer porque José Domingo Romero, hijo de los ya nombrados, quiso hacer valer sus derechos sobre las mismas en 1858. Es probable que durante la Guerra Grande, dichas fincas hayan pasado al fisco, como sucedió con casi todos los solares del país. Cuando Toribio Palmerola compró sus primeras tierras en ese lugar ( 875 ), aquello era conocido como Isla Romero kue"

19 PASTORE, op. cit., pp. 179 ss.

20 Ver nota no 6.

2I No se han encontrado las partidas de bautismo de las niñas; las fechas de nacimiento las obtuvimos de los descendientes de los Bruyn Palmerola.

22 Archivo Arzobispal de Asunción. Matrimonios. Luque (1870-1889). Por la importancia que reviste este documento, lo trascribimos íntegro a continuación: "Luque 7 de diciembre de 1888. Ayer seis de diciembre a las siete de la noche, me mandó decir don Toribio Palmerola, residente argentino que vive en este Partido a una legua del pueblo, que se hallaba gravemente enfermo y se sentía en peligro y quería desposarse `lo más pronto posible ’ con una señora llamada Carlota Ayala que tenía consigo hace muchos años a fin de llenar un deber de conciencia y legitimar a sus hijas naturales. Para el efecto me constituí en su casa habitación y constatando el peligro que el pretendiente alegaba y no habiendo tiempo de recurrir a la Curia Episcopal para 
obtener dispensas de proclamas, teniendo el infrascrito facultad de dispensar, los dispensé a los pretendientes in facia Eclesiae según rito, previa las demás formalidades de derecho. Fueron testigos de soltería: Sión Sosa, que dijo conocerlo desde hacía nueve años y Gabriel Colmán que lo conoce hace 10 años. Este procedimiento se hizo en su casa el día de la boda. Testigos de la ceremonia: Sión Sosa y Lorenza Ayala. Firma: Claudio Arrúa - Cura de la Parroquia de Luque. Asunción, 14 de diciembre. Acepta el caso Tomás Antonio Castelví - Cura Rector de la Catedral".

23 Archivo del Registro General de la Propiedad. Pirayú. Protocolo 308, Tomo III, f. 498. La venta se efectuó el 19 de mayo de 1884 entre la Sociedad Toribio Palmerola Hno y el vendedor Juan Freitas Travassos, dueño de innumerables latifundios adquiridos en la post guerra. Dichas tierras medían una legua y 55 varas, por una legua y media de fondo y se hallaban alambradas, mensuradas y amojonadas desde 1874; según los antecedentes de título, Travassos las había adquirido de Saturnina Caballero. Con la disolución de la sociedad, tras la muerte de Toribio, su parte le correspondió a Carlota Ayala y sus dos hijas y la de José Palmerola a sus herederos José del Simón, Félix y Vicente Palmerola. La propiedad fue vendida luego a Tomás Romero Pereira y hoy pertenece a su hija, Susana Romero de Puente.

24 Archivo del Registro General de la Propiedad. Protocolo I884, Primera Sección, Tomo II, No. 690, f. 275. En fecha nueve de agosto de 1884, Dominga Fernández de Patiño, vecina de Paraguari, vendió a Toribio Palmerola, vecino de Luque, una casa de tejas. Su frente al norte en vera sur de la calle Igualdad ( 25 de Mayo) de 18 varas y un pie por igual contrafrente al sur que linda con Francisco Soteras, de fondo en ambos costados mide 36 varas y un pie lindando al oeste con Francisca Salcedo y al este con los de Bruguez., hoy del comprador. Pagó por ella 2.000 pesos fuertes en moneda de curso legal, al contado. Una nota marginal escrita en el año 1900 deja constancia que la propiedad quedó a manos de Ramona Josefa Palmerola de Bruyn y Antolina Dolores Palmerola de Aceval. Folio I.0 I 0 vto. y s. del Registro de la Propiedad correspondiente a 1900.

25 Archivo del Registro General de la Propiedad. Protocolo 1885, nº 85, Ia sección, tomo I, f. I.

26 Archivo del Registro General de la Propiedad. Protocolo I886, nº 279, tomo IV, f. 769. Esta propiedad se encontraba ubicada en las calles Azara y Loreto (México).

27 Archivo del Registro General de la Propiedad. Protocolo 1886, n | 53 I, f. I I 47 vta. Al parecer, este inmueble entró en la sociedad, ya que al fallecer Toribio en 1893, el mismo pasó a su hermano José Palmerola, según consta en folios 497 y siguientes del RGP correspondiente al año I893. E. Varela.

28 PUCHEU, op. cit. p. 19.

29Archivo Arzobispal de Asunción. Soltería I895- | 896. Cornelio Bruyn, de nacionalidad holandesa, contaba entonces con 30 años de edad; era hijo de Cornelio Bruyn y Juana Leguit y estaba domiciliado en Cerro León - Pirayú. Presentó como prueba de su soltería una carta escrita desde Holanda por un hermano suyo en la que lo felicitaba por su próxima boda.

30 Archivo Arzobispal de Asunción. Matrimonios. Catedral de Asunción. Libro IV, Años I8931903. Asunción 15 de febrero de 1896. Certificado de matrimonio de Héctor Aceval con Antolina Dolores Palmerola, ambos menores de edad; en el mismo se autoriza la celebración del matrimonio en el domicilio de las novias; firma el documento, el presbítero Francisco S. Franco. A renglón seguido se consigna el matrimonio de Cornelio Bruyn y de la menor Ramona Josefa Palmerola, seguido de los mismos datos consignados en el certificado anterior.

3IArchivo Arzobispal de Asunción. Bautismos - Catedral. Libro XIV 1995-1900 / Libro XV 1900-1906 y Libro XIX 1914-1917. Todos los nietos de Carlota fueron bautizados en la Catedral, las dos últimas por el P. Aníbal Mena Porta, el 28 de noviembre de 19|4, siendo la abuela, madrina de ambas: Edulia Cora y Juana Carlota Bruyn Palmerola. 
32 Archivo del Registro General de la Propiedad. $18995^{a}$ Sección. No. 625, f. 1051 y ss. En fecha 23 de agosto de 1897 se procedió a la compra-venta de las nueve fracciones de tierras, las cuales abarcaban de oeste a este, desde la actual Avenida del Lago hasta Isla Valle. Tal como exige la ley, del total de fincas se descontaron en este caso dos cuadras y media para utilidad pública y construcción de un embarque sobre el Lago Ypacarai.

33 Archivo del Registro General de la Propiedad. 1899 5ta. Sección. No. 625, f. I05I y ss. La inscripción en el Registro General de la Propiedad está fechada el 26 de julio de 1899.

34 La Tribuna, domingo 2 I de julio de 1974. Historias, recuerdos y la curiosa leyenda del castillo de Areguá, p. 14, sin En el Registro General de la Propiedad hallamos a un Carlos Hoffer, que pudo haber sido el mismo del que hace mención dicho diario; éste había comprado una propiedad en el distrito de San Roque en 1902 y otra en 1904.

35 lbídem.

36 Archivo del Colegio San José. Certificados de Estudios Secundarios de Juan Carlos Aceval Palmerola (191|-1916) y Toribio Bruyn Palmerola (1909-19|4). Durante los seis cursos de la secundaria, Juan Carlos estuvo eximido de hacer gimnasia, la cual habla de su debilitada salud física.

37 Hemos recurrido al Archivo del Colegio María Auxiliadora para obtener copia de sus primeras calificaciones pero no guardan registros de los primeros años de fundación. Dicha institución se fundó en 1900 y se sabe que el Presidente de la República, Emilio Aceval, tío abuelo de Dianora, costeó de su peculio el viaje de las primeras religiosas que vinieron de Europa y el Uruguay para el efecto.

38 El chalet de Cornelio Bruyn y Josefa Palmerola es conocido hoy como Quinta Facetti.

39 A la pelota vasca se la conoce popularmente como frontón por ser el lugar donde se juega. 40 Lápida que recuerda su defunción con las fechas de su nacimiento y muerte. Panteón de los Palmerola, en el Cementerio de la Recoleta de Asunción.

4I Una de las placas recordatorias puestas en la fachada del templo de Areguá está dedicada a doña Carlota Ayala de Palmerola, que junto con Teodosio González y su esposa Asunción González fueron los principales benefactores de aquella obra.

42 PUCHEU, op. cit. p. 79.

43 El Diario, 12 de enero de 1923.

44 Discursos pronunciados en la Recoleta ante los restos de Emilio Aceval Palmerola. Pucheu, op. cit. pp. y 158 y ss. Pucheu, op. cit. pp. y 158 y ss.

45 El Diario del 13 de febrero de 1926. La bendición de dicha imagen estuvo a cargo de Monseñor Hermenegildo Roa, la misma formó parte del programa de festejos patronales de la Virgen de la Candelaria.

46 Archivo Arzobispal de Asunción Comunicación Oficial del Arzobispado. Año 1937. Monseñor Juan Sinforiano Bogarín, otorgó a la nueva capilla de doña Carlota el "privilegio vitalicio de 'Oratorio Privado' con licencia de mandar celebrar cada día y con su asistencia una misa encargada por ella y no por otra persona, aun en los días más solemnes del año, exceptuando perpetuamente las fiestas de Navidad y de la Pascua de Resurrección y de la Virgen de la Asunción". Dicho comunicado se hizo en dos copias: una para la Curia Arzobispal y otra para que sea colocada en lugar visible en el mismo Oratorio, junto al Breve Pontificio del 8 de mayo del mismo año. La nota fue suscrita en el Palacio Arzobispal, el 23 de junio de 1937 y firmada por monseñor Juan Sinforiano Bogarín y Agustín Bogarín Argaña, como secretario interino. 47 Archivo Arzobispal. Hermanas Dominicas del Santísimo Sacramento, Volumen III /432.7. 48 Archivo Arzobispal. Autos y Decretos de S. E. Rvdma. Monseñor Aníbal Mena Porta. Julio de 
1950 a junio de 1961. Libro 5to, f. 13. Decreto No. 2. "Nos, Aníbal Mena Porta por la gracia de Dios y la Santa Sede Apostólica, Arzobispo de Asunción. Habiendo fallecido en esta capital la señora Doña Carlota Ayala de Palmerota, tan ligada a la Iglesia por sus obras de cardad, realizada en silencio y gran modestia, como lo fuera toda su austera vida. Por tanto, en testimonio de nuestro profundo reconocimiento, venimos a disponer en su memoria los siguientes actos. $1^{\circ}$ - En su domicilio, donde se vela su cadáver, celébrese una Misa de cuerpo presente por un sacerdote de nuestro Seminario Metropolitano, institución amada por la extinta y que recibiera de sus manos ponderable ayuda. $2^{\circ}$ - En Areguá, cuya Iglesia en gran parte y la Casa Parroquial totalmente fueron restauradas con su aporte pecuniario, se rezará en el templo parroquial por el eterno descanso de su alma, invitándose a los fieles para este acto piadoso doblando las campanas durante el novenario a cuyo término se oficiará un funeral. $3^{\circ}$ - En la Casa Madre de las Hermanas Misioneras Parroquiales de Luque, protegida de la benemérita extinta, las religiosas rezarán también en su capilla doméstica un novenario finalizando con una Misa de Requiem. $4^{\circ}$ - Reservámonos presidir la inhumación de sus restos mortales en el Cementerio de la Recoleta, debiendo estar al servicio del altar a cargo del Seminario Metropolitano. Comuníquese a quienes corresponda y luego archívese. Dado en el Palacio Arzobispal a los 16 dias del mes de mayo de mil novecientos cincuenta y uno.

Comuníquese a quienes corresponda y luego archívese. Dado en el Palacio Arzobispal a los 16 dias del mes de mayo de mil novecientos cincuenta y uno.

49 Archivo de la Congregación de las Hermanas Dominicas. Título y Planos. Escritura de compraventa de una fracción de terreno en Areguá. Año 1959. Según el informe pericial presentado por el agrimensor público Luis E. Ferreira, a pedido de doña Antolina Dolores Palmerota de Aceval, el 23 de enero de 1958, los límites de la fracción que entregaría a las Dominicas contaba con las dimensiones y linderos siguientes: "Línea I-2 mide cincuenta y tres metros, con rumbo Norte $55^{\circ}$ Oeste y linda con la Vía Férrea del F.C.C.P. La línea 2-3 mide diez metros con rumbo Norte. $25^{\circ} 34^{`}$ Este y linda con la misma Vía Férrea. Línea 3-4 mide sesenta y tres metros con rumbo Norte 53 5 I Oeste, linda con la misma vía. Línea 4-5 mide ciento ochenta metros, sesenta centímetros con rumbo N. $25^{\circ} 7^{`}$ Este, linda con derechos de la Señora Palmerota viuda de Aceval. Línea 5-6 mide ciento veinticinco metros con rumbo Sur $47^{\circ} 46^{`}$ Este linda parte con derechos de la Señora Palmerota viuda de Aceval. Línea 6-7 mide treinta y tres metros Sur $36^{\circ} 41^{\prime}$ 'Oeste, linda con derechos de doña Cora Edulia Regina Bruyn. Línea 7-8 mide diez y nueve metros treinta centímetros con rumbo Sur $51^{\circ} 9^{\circ}$ Este, linda con más derechos de la señora viuda de Aceval. Línea 8-I mide ciento cuarenta y nueve metros treinta centímetros, con rumbo Sur $32^{\circ} 55^{`}$ Oeste, linda con una calle pública. Superficie: Dos hectáreas, dos mil seiscientos treinta y cuatro metros cuadrados y seis mil seiscientos centímetros cuadrados. Referencia: El punto indicado en el plano con el número I se halla a veintitrés metros del punto A situado sobre la línea I-8. El mojón de referencia es de madera e indica la separación de la fracción deslindada de la calle que conduce al lago".

50 Archivo Arzobispal. Hermanas Dominicas del Santísimo Sacramento III / 432.7 